Document downloaded from:

http://hdl.handle.net/10251/158682

This paper must be cited as:

De-Miguel-Gallo, M.; Martinez-Capel, F.; Muñoz Mas, R.; Aihara, S.; Matsuzawa, Y.;

Fukuda, S. (2019). Habitat evaluation for the endangered fish species Lefua echigonia in the Yagawa River, Japan. Journal of Ecohydraulics. 4(2):147-157.

https://doi.org/10.1080/24705357.2019.1614886

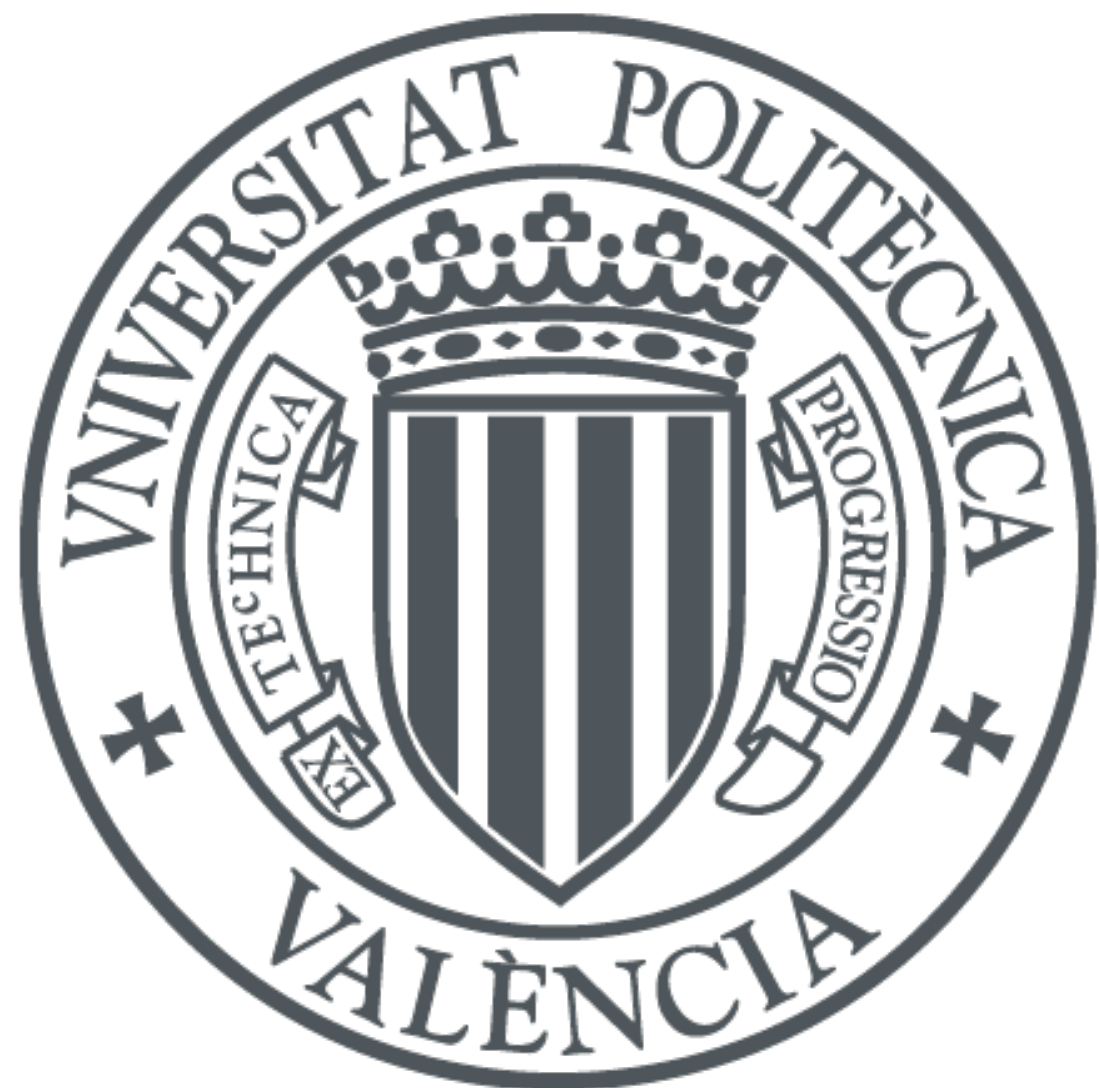

The final publication is available at

https://doi.org/10.1080/24705357.2019.1614886

Copyright Taylor \& Francis

Additional Information

This is an Accepted Manuscript of an article published by Taylor \& Francis in Journal of Ecohydraulics on 2019, available online:

http://www.tandfonline.com/10.1080/24705357.2019.1614886 


\title{
Habitat evaluation for the endangered fish species Lefua echigonia in the Yagawa River, Japan
}

\author{
M. De-Miguel-Gallo, ${ }^{\text {a }}$, F. Martínez-Capel ${ }^{\mathrm{a}, *}$, R. Muñoz-Mas ${ }^{\mathrm{b}, \mathrm{a}}, \mathrm{S}$.

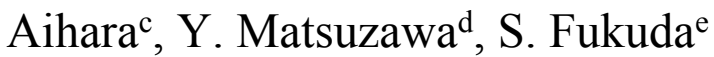 \\ * Both authors contributed equally to this work.
}

anstitut d'Investigació per a la Gestió Integrada de Zones Costaneres (IGIC), Paranimf, 1. Universitat Politècnica de València (UPV), Gandia, Valencia 46730, Spain

${ }^{b}$ GRECO, Institute of Aquatic Ecology, University of Girona, Catalunya, Spain

${ }^{c}$ Institute for Rural Engineering, National Agriculture and Food Research

Organization, 2-1-6 Kannondai, Tsukuba, Ibaraki 305-8609, Japan

${ }^{d}$ Public Works Research Institute (PWRI), Minamihara 1-6, Tsukuba, Ibaraki 3058516, Japan

e Institute of Agriculture, Tokyo University of Agriculture and Technology, Saiwai-cho 3-5-8, Fuchu, Tokyo 183-8509, Japan

Full correspondence details here including e-mail for the * corresponding author:

F. Martínez-Capel. Institut d'Investigació per a la Gestió Integrada de Zones Costaneres (IGIC), Paranimf, 1. Universitat Politècnica de València (UPV), Gandia, Valencia 46730, Spain.fmcapel@dihma.upv.es 


\title{
Habitat evaluation for the endangered fish species Lefua echigonia in the Yagawa River, Japan
}

\begin{abstract}
Spring-fed streams in Tokyo are important habitats for various aquatic species, whereas urbanisation as well as introduction of invasive species are threatening the sustainability of such aquatic ecosystems. This study applies the System for Environmental Flow Analysis (SEFA) in a small urban river in Tokyo to assess the dynamics of the suitable habitats for the endangered freshwater fish Lefua echigonia (Jordan \& Richardson 1907). A set of Habitat Suitability Curves (HSCs) for water depth, velocity and substrate was developed to evaluate the suitable habitats. The habitat assessment indicated that the Area Weighted Suitability (AWS) reached the maximum at $0.02 \mathrm{~m}^{3} / \mathrm{s}$, which is close to the base flow of the target river; a gradual decrease in AWS was observed for higher flows. The temporal distribution of AWS, during forty-one consecutive months, showed that, on average, the best habitat conditions for adult L. echigonia occur during the period between January and July, whereas the worst situation occur during the period between August and December. This work presents information and tools for instream habitat analysis that should help managers to conserve this aquatic species and prioritize actions to further rehabilitate urban rivers, using $L$. echigonia as a case study.
\end{abstract}

Keywords: Environmental flow assessment, instream habitat simulation, habitat suitability curve, hydraulic modelling, small-bodied fish, spring-fed urban stream

\section{Introduction}

Urbanisation has led to a significant degradation and biodiversity loss of nestled river catchments due to increases in pollutants concentrations, modifications of river banks and hydrological alteration (Coelho et al. 2014). An acknowledged side-effect is the process by which cities phagocytise endemic-species distribution areas (e.g. McDonald et al. 2018); the extreme case is that of the Ambystoma mexicanum (Shaw and Nodder, 1798) whose natural distribution area is restricted to a few ponds of Mexico City 
(Recuero et al. 2010). Despite the relevance of urban rivers from an anthropocentric perspective due to the number of ecosystem services they provide (i.e. nonmaterial benefits that people obtain from nature such as aesthetic values, cultural heritage or recreation) (Vollmer et al. 2015), the expected rates of metropolis development suggest these processes are unlikely to discontinue over the $21^{\text {st }}$ century (Sardak et al. 2018).

Tokyo has undergone a wide and rapid development and urbanisation process after WWII (Taniguchi et al. 1999), which alike other large conurbations had a significant impact on the enclosed fluvial ecosystems (Vollmer et al. 2015). Tokyo river catchments originally suffered the impact of several channel modification works, especially concrete-lining that turned them into irrigation channels, which were extensively implemented to increase agricultural productivity resulting into deterioration and fragmentation of river habitats (Fukuda et al. 2015). As it has been observed for other urban streams (e.g. Lee et al. 2010), Tokyo streams have been subsequently managed and exploited with an emphasis on both flood control and instream water uses.

The urban area of Tokyo city has already engulfed partially the restricted distribution area of the native fish species Lefua echigonia (Jordan \& Richardson 1907) (fam. Balitoridae), which may become a key species for the aquatic biodiversity conservation in spring-fed streams in the eastern part of Japan. Nonetheless, this species was listed as an endangered species by the Environmental Ministry of Japan (category: EN) (Hosoya, 2003). The genus Lefua has a very small distribution area in the world; it can be found in the Amur drainage (Korea), north-eastern China and Japan, where only 7 species have been described globally (Kottelat 2012). Despite the ecological importance of these species, there is no available information about their habitat requirements. Thus, it is only known that they usually inhabit small headwater streams 
in lowland areas (Mitsuo et al. 2009). To fill this knowledge gap, a microhabitat suitability model was developed for adult Lefua echigonia in this study.

The Yagawa River (Tokyo, Japan) is a representative of general problems for a significant number of small spring-fed urban rivers and streams in Tokyo, where the loss of natural habitats and habitat diversity due to urbanization and river modification are jeopardizing the sustainability of the aquatic communities (Mitsuo et al., 2009). In this situation, the conservation of endemic species, and more specifically L. echigonia and accompanying species, should become a key in biodiversity sustainability. An additional indication of its value is that this fish is thought to be a key host fish for glochidia of Unionidae (Toshishige and Maruyama, 2005). In this regard, the study of species-environment relationships, to later evaluate the impact of different flow regimes, can offer a way to understand the impact of further habitat manipulations such as restoration of nature-like substrates in a concrete-lined section, together with an improved watershed management including rainfall infiltration for spring water restoration in urban and residential areas, which may favour biodiversity conservation.

The natural flow regime (sensu Poff et al. 1997) has been stated to be the master variable that shaped fish assemblages and triggered species adaptation and evolution (Poff 2010). This regime is profoundly altered by river regulation and water diversion, which becomes deleterious to native fish communities. Therefore, the establishment of environmental flows (i.e. the quantities, quality, and patterns of water flows) to balance protection of natural environment with out-of-stream uses is a worldwide enterprise (Rosenfeld 2017).

Despite the debate, the physical habitat simulation approach (Bovee et al. 1998) is still considered the most defendable approach, from a legal perspective, to evaluate the impact of different flow regimes on the habitat suitable for the target freshwater taxa 
(Reiser \& Hilgert 2018). It combines habitat suitability models with hydraulic simulation and hydrological data to determine the most appropriate environmental flow regime. In accordance it has become not only useful for regulated streams, but also to know the environmental requirements before any development plans are made (O’Keeffe \& Quesne 2009).

The first objective of this study was to develop a habitat suitability model for the fish species L. echigonia in the Yagawa River. The second one was to implement the physical habitat simulation method in this river. And the third one, to recommend key rehabilitation measures for this river, based on the spatial and temporal analysis of habitat availability in terms of the Area Weighted Suitability (AWS); i.e. the habitat indicator usually termed Weighted Stitable Area (WUA) divided by river length.

In summary, this research presents fundamental ecological information concerning microhabitat use and physical habitat simulation in order to help managers conserve the endemic fish species and prioritize actions of urban river rehabilitation, not only for L. echigonia but also for other benthic fish species in Japan and East Asia.

\section{Methods}

\section{Study area and target species}

The Yagawa River is a 1500-meter-long free-flowing stream located in Kunitachi (i.e. outskirts of Tokyo, Japan) (Matsuzawa et al. 2017b). The river runoff is groundwaterfed (the spring of the river provides the highest flow around October), although it responds rapidly to episodic events of intense rainfalls caused by typhoons (usually in August and September). The riparian habitats present a notable longitudinal variability 
with well forested areas intersected with channelized sections. The river is connected to the Fuchu Yosui irrigation system and contributes to the Tama River (Figure 1).

[Here Figure 1]

To obtain dedicated data on the actual flow regime, the flow was gauged monthly at station 2 (Figure 1) from June 2015 to October 2018 (Figure 2). In this period, the maximum monthly runoff was observed in October/November, whereas the minimum runoff occurred in February/March, followed by a period of stable base flow —only interrupted by storms - that lasted approximately 6 months.

[Here Figure 2]

Lefua echigonia is a small benthic fish (total length $<10 \mathrm{~cm}$ ) with relatively low swimming ability (Matsuzawa et al. 2017a). The adults burrowed into sand or under stones and stay in slow currents or static waters (Mitsuo et al. 2007, Aoyama et al. 2007), feeding principally from benthic or planktonic invertebrates (Mitsuo et al. 2009). The individuals mature between the first and second year and the breeding season takes place from late March to early June. The females lay adhesive eggs on litter, leaves, aquatic vegetation or under stones and substrate interstices to avoid scouring (Mitsuo et al. 2009; Aoyama et al. 2005; Hosoya 2003); the latter is considered an adaptation to mountainous conditions (Aoyama and Doi 2005). This fish species can be considered as very sensitive to channelization affecting natural substrate, as well as habitat alterations related with flow velocity and with any type of barriers that affect longitudinal and lateral connectivity. 


\section{Data collection}

The fish sampling (presence or absence) in the entire reach of the Yagawa River was repeated every month from June 2015 to May 2017 by a hand net covering all the present mesohabitat types (i.e. pool, run, riffle) in order to capture the largest spatial and temporal variability (Martínez-Capel et al. 2009; Muñoz-Mas et al. 2017). Concomitantly, mean water column velocity (hereafter velocity; $\mathrm{m} / \mathrm{s}$ ) and depth $(\mathrm{m})$ at the sampling spot were collected at the microhabitat scale. Velocity was measured with a current meter (VP30, KENEK, Tokyo, Japan) and depth was measured with a wading rod to the nearest millimetre. In addition, the percentage of substrate classes was visually estimated following previous studies (Martínez-Capel et al. 2009; Muñoz-Mas et al. 2017); 1, vegetation; 2 , sand $(\varnothing \leq 2 \mathrm{~mm}) ; 3$, small-sized gravel $(2<\varnothing \leq 16 \mathrm{~mm})$; 4, medium-sized gravel $(16<\varnothing \leq 64 \mathrm{~mm}) ; 5$, large-sized gravel $(\varnothing>64 \mathrm{~mm}) ; 6$, concrete and continuous rock. Physical habitat measurement was additionally performed where fish was absent for better illustrating species specific habitat suitability. During this 2-year survey, flow discharge ranged from $0.002 \mathrm{~m}^{3} / \mathrm{s}$ to $0.3 \mathrm{~m}^{3} / \mathrm{s}$ which covers almost all flow dynamics in the river. Immature fish presented an even distribution across the river specifically after their emergence (i.e. with evident lack of habitat selection), thus we focused exclusively on the habitat selection shown by adults.

\section{Habitat suitability model}

The relationship between the hydraulic variables and their suitability (suitability index, SI) was mathematised with univariate habitat suitability curves (HSCs) (Waters 1976) based exclusively on presence observations (i.e. Use or category II HSCs) (Bovee 1986). For each of the three variables (velocity, depth and substrate), frequency histograms were built considering exclusively the data collected in the sampling spots where at least one individual was observed (presence data). The histograms were 
normalised between 0 and 1, and the right tail indicating very low suitability (suitability index $\leq 0.1)$ were set to 0.1 in order to fill intervals without data. Given the large quantity of microhabitat data (presence/absence observations covering the entire river), this procedure meant no subjective intervention on the resulting curves. The microhabitat selection (non-random use) was statistically tested —use or presence versus availability or absence data (Hayes and Jowett, 1994; Martínez Capel 2000)_ with a Mann-Whitney U two-sample test $(p<0.05)$ using STATGRAPHICS Centurion XVII software ver. 17.2.04 (2014 Statpoint Technologies, Inc. USA).

\section{Hydraulic modelling}

The software tool SEFA (System for Environmental Flow Analysis; Payne and Jowett 2012; Jowett et al. 2014), which follows the scheme of the Instream flow Incremental Methodology (IFIM, Bovee et al. 1998), was used to perform the physical habitat simulation. With SEFA, a one-dimensional hydraulic model was generated and calibrated, based on the cross-sections - 108 sections covering the 1338-m-long segment - and water surface elevation data from field surveys (collected with an optical levelling instrument). The calibration flow was calculated as the trimmed mean flow rate considering the gauges obtained in every transect ( $10 \%$ out). The module for Water Surface Profile (WSP) modelling, based on the common standard-step calculation method, was used to simulate representative river flow rates $\left[0.01,0.20 \mathrm{~m}^{3} / \mathrm{s}\right]$ based on the gauged flows described above (June 2015 - October 2018).

\section{Habitat evaluation}

The reach Area Weighted Suitability (AWS) $\left(\mathrm{m}^{2} / \mathrm{m}\right)$ - usually termed Weighted Usable Area - WUA (Bovee et al., 1998) but in terms of $\mathrm{m}^{2}$ per metre of river length-, was calculated for every simulated flow. The SEFA software calculates first, the Composite 
Suitability Index (CSI), by multiplying the habitat suitability (between 0 and 1) for the three microhabitat variables, namely depth, velocity and substrate, at each measurement point or simulation cell (Muñoz-Mas et al. 2012; Jowett et al. 2014). The AWS is calculated by evaluating the CSI at each model cell (CSI), then multiplying it by the proportion of the reach area represented by that cell and summing over the reach (Jowett et al. 2014). In order to characterise the spatial variability of habitats available for $L$. echigonia, a longitudinal distribution of AWS for several flow rates was calculated. Finally, a time series of AWS was calculated to represent the temporal variability of $L$. echigonia habitats along the Yagawa River from June 2015 to October 2018. The latter was performed at the monthly time scale.

\section{Results}

The habitat characterisation demonstrated the diversity of microhabitats measured during the two years of regular surveys (Figure 3), across 108 transects located in $1381.5 \mathrm{~m}$ long of the Yagawa River. The range of the microhabitat variables reached a maximum velocity of $1.068 \mathrm{~m} / \mathrm{s}$, maximum depth of $0.40 \mathrm{~m}$; all the substrate types were present, and channel wetted width ranged from 1.10 to $4.65 \mathrm{~m}$. The distribution of substrate classes along the cross sections in the river reach is shown in Figure 4. A total number of 406 presence data were collected for adult individuals of L. echigonia; the number of absence data was 2775. The results of the Mann-Whitney tests showed a non-random use of the microhabitats $(p<0.05)$, i.e. a significant statistical difference (presence versus absence data) in both depth and velocity. This indicated that $L$. echigonia was performing an active habitat selection in the Yagawa River.

[Here Figure 3] 
[Here Figure 4]

The HSCs (Figure 5) showed that the highly suitable depth (SI $>0.5)$ for the adult $L$. echigonia in the Yagawa River ranges from 0.043 to $0.15 \mathrm{~m}$, reaching the maximum suitability at a depth around $0.075 \mathrm{~m}$. Based on our observation, the suitability was set to 0.1 for areas deeper than $0.17 \mathrm{~m}$. The suitable range of mean velocity was observed between 0.00 and $0.09 \mathrm{~m} / \mathrm{s}$, with the maximum suitability for velocities equal or smaller than $0.05 \mathrm{~m} / \mathrm{s}$. The presence data were scattered beyond $0.20 \mathrm{~m} / \mathrm{s}$, thus the suitability index for that range was set to 0.1 , founded on the knowledge that the swimming ability of this fish species is very limited at velocities over $0.2-0.3 \mathrm{~m} / \mathrm{s}$ (Matsuzawa et al., 2017a). In terms of substrate, vegetation and large gravel were the most suitable types. On the contrary, concrete or continuous rock was considered unsuitable. Concerning silt and boulders, these types were not observed in the study site. Nevertheless, there are 8 substrate classes listed in Figure 5 (including those aforementioned) because the HSCs must fit the categories described in the SEFA software.

[Here Figure 5]

The stream flow was calculated using all the 108 transects surveyed (cross-sections), resulting in the calibration flow of $0.044 \mathrm{~m}^{3} / \mathrm{s}$. The precise measurement of the topography, water surface elevation and mean velocity in these transects allowed the calculation of the Manning's roughness coefficient N (ranging between 0.03 and 0.17 ). The survey results indicated the most reliable data between transects 9 and 76 (with a relevant hydraulic jump above transect 76), thus the calibration of the hydraulic model was performed there. The sensitivity analysis showed negligible sensitivity to errors in 
water surface elevations in the transect number 13 and upstream until transect 76, where the physical habitat condition was evaluated. Therefore, the total length of the simulation reach was of $805 \mathrm{~m}$, representing $60.2 \%$ of the total measured length. At the calibration flow, the AWS for the simulation reach was $0.360 \mathrm{~m}^{2} / \mathrm{m}$, representing the availability of suitable habitat for the time of the survey, i.e. the week from the $28^{\text {th }}$ May to the $3^{\text {rd }}$ of June 2018 . The curve relating AWS with river flow rate showed the highest value at a flow of $0.020 \mathrm{~m}^{3} / \mathrm{s}$, for which the AWS representing the whole simulation reach gets a value of $0.465 \mathrm{~m}^{2} / \mathrm{m}$ (Figure 6). The curve slowly goes down and tends to the lowest value, approximately $0.150 \mathrm{~m}^{2} / \mathrm{m}$, which corresponds to the highest simulated flow, $0.200 \mathrm{~m}^{3} / \mathrm{s}$.

[Here Figure 6]

On the spatial distribution of the AWS per transect an irregular pattern was observed, with ample differences in habitat conditions (i.e. a range from near to zero to $1.89 \mathrm{~m}^{2} / \mathrm{m}$ (Figure 7). The general trend showed that higher flows produced smaller amounts of habitat availability. Therefore, the highest values of AWS were observed during the lowest flow rate $\left(0.010 \mathrm{~m}^{3} / \mathrm{s}\right)$ in five groups of transects alternating with areas of low suitability, in the upper part of the simulation reach. These groups of suitable transects correspond in every case to pool-type mesohabitats, where at the calibration flow the mean depth was larger than the average, mean velocity was lower than the average, vegetation was not present or was very scarce and the proportions of concrete were relevant (XS 37-40, XS 44-45, XS 48-51, XS 58-61, XS 64, in Figure 4). On the contrary, in a small group of transects, the highest values of AWS were achieved at the flow rates of 0.150 and $0.200 \mathrm{~m}^{3} / \mathrm{s}$ (XS-4 corresponding to station 2; and XS-11, 12, 
13). These transects encompassed habitats where at the calibration flow the mean depth was equal or smaller than the average, mean velocity was similar or higher than the average and substrate was natural (concrete was mostly absent) regardless the mesohabitat type (run, riffle and pool).

\section{[Here Figure 7]}

The temporal distribution of AWS, during forty-one consecutive months, indicated that, on average, the best habitat conditions for adult L. echigonia occurred during the period between January and July (Figure 8). However, the year 2018 showed a particular situation because there was an extreme event when the river flow was almost depleted during February $2018\left(0.002 \mathrm{~m}^{3} / \mathrm{s}\right)$; and in the following months, the availability of suitable habitat, in terms of AWS, was relatively low in comparison with the previous two years. In general, the period with the lesser habitat availability corresponded to the months between August and December. In September 2015, 2016 and 2018 the lowest values of habitat availability were recorded, with AWS between 0.142 and $0.158 \mathrm{~m}^{2} / \mathrm{m}$. Similarly, the minimum habitat in November 2017 corresponded to $0.142 \mathrm{~m}^{2} / \mathrm{m}$. On the contrary, the highest values corresponded to February $2016\left(0.464 \mathrm{~m}^{2} / \mathrm{m}\right)$, with a flow rate of $0.02 \mathrm{~m} / \mathrm{s}$, the period of April-June 2017 (ca. $0.464 \mathrm{~m}^{2} / \mathrm{m}$ ), with similar flow rate, and January 2018 with the same values in AWS and flow rate. This means that for the recorded range of flows, the AWS can span up to three-fold the lowest value.

[Here Figure 8] 


\section{Discussion}

The first objective of developing habitat suitability curves (HSCs) for adult Lefua echigonia in the Yagawa River was successfully completed. The HSCs allow for the implementation of the physical habitat simulation in this and other similar rivers with similar geomorphology and hydrological dynamics, although a validation procedure (i.e. transferability test) should be strongly encouraged (e.g. Thomas \& Bovee, 1993). This is one of the first studies of habitat simulation in small spring-fed urban rivers of Tokyo (see Matsuzawa et al. 2017b), which makes it relevant for the biodiversity conservation of urban small spring-fed rivers. Consequently, any derived management plan should help those rivers (very abundant around the fluvial terrace of the Tama River where a part of metropolitan area spreads) to sustain healthy aquatic environments and native species. Furthermore, the accumulation of knowledge of smallbodied fish can provide relevant information for conservation and restoration planning and for the management of diverse ecosystems or species (Fukuda 2011).

Although stream flow and other factors affect the microhabitat use by fish (e.g. Orth 1987; Lambert 1994; Martínez-Capel 2000), in this study, the bias related with survey data was considered very improbable because the microhabitat data were very abundant $(N=406$ presence data) and the test for non-random use, demonstrated that habitat selection was correctly identified. In addition, microhabitat data were collected during a relatively long period (24 months), and under a wide range of microhabitat conditions considerably ampler than those selected by the fish.

The HSCs exhibited the microhabitats selected by this fish species, offering the first description of the fish behaviour at the microhabitat scale in the wild, and consequently of the habitat dynamics as the flow changes across seasons. The HSC for velocity showed the selection of L. echigonia for quiet and very slow waters, preferably 
below $0.09 \mathrm{~m} / \mathrm{s}$; this result resembles previous studies, which indicated that adults usually stay in slow currents or static waters (Mitsuo et al. 2007). To the best of our knowledge, there exist some reports on microhabitat use of this fish species, but they are limited to specific habitats like spring-fed pool-like habitats and ponds. Other fish of the same family have received more attention, especially concerning some Eurasian species, such as the stone loach, Barbatula barbatula (L., 1758). This fish has been associated with an ample variability of microhabitat use (Copp \& Vilizzi, 2004), in relation with different factors, e.g. ontogenetic status, time of day, and food availability, but in general selecting low flow velocity $(0.05-0.10 \mathrm{~m} / \mathrm{s})($ Copp, 1992). Thus, demonstrating a great coincidence with our results for L. echigonia. On the other hand, in accordance with that plasticity in habitat use demonstrated by other similar species, Lamouroux \& Capra (2002) described the interval of suitable mean velocity for the stone loach (suitability index $>0.5$ ) between ca. 0.1 and $0.8 \mathrm{~m} / \mathrm{s}$. These results suggest that L. echigonia may depict a greater plasticity in terms of habitat selection in other rivers with different habitat conditions.

In the Yagawa River, the maximum recorded velocity $(>1 \mathrm{~m} / \mathrm{s})$ demonstrated the ample range of conditions of this study area. However, the highest high velocities coincided in a greater proportion to large-sized gravel substrates that can create a slowly flowing microhabitat around them. Further study is needed for a deeper understanding of L. echigonia microhabitat uses under high velocity conditions, leading to an improved habitat assessment even under what can be currently considered unsuitable conditions. The habitat selection in terms of depth indicated a high suitability of very shallow waters, mainly between 0.04 and $0.13 \mathrm{~m}$, while the available microhabitats sampled reached $0.40 \mathrm{~m}$ depth, which foregrounds the very small size of the river. This observation generally matches former studies, which indicated that L. echigonia 
inhabits shallow, slowly-flowing streams and ponds where the natural environment has been well conserved (Hosoya, 2003). The selection of shallow waters could be related with the banks where vegetation was frequent, since different authors have identified vegetation as a favourite substrate for depositing the eggs (Mitsuo et al., 2009).

An analogous reasoning can be performed regarding the relatives of the family Cobitidae of Europe, since the stone loach Noemacheilus barbatulus (L., 1758), the kissing loach Leptobotia curta (Temminck \& Schlegel, 1846), the small striated spined loach Cobitis sp., and the middle striated spined loach Cobitis sp., are known to use spaces among submerged plants for their spawning site (see Aoyama \& Doi, 2006, including further references therein). Similarly, Bohlen (2003) demonstrated that Cobitis taenia (L., 1758) showed a strong preference for dense vegetation as a spawning substrate in German rivers; it was then hypothesized that vegetation provides sheltering environments as decreasing egg predation and as preventing eggs from drifting away even in rapid currents (Bohlen, 2003). Another study on stone loach (B. barbatula), also indicated a strong preference for shallow microhabitats with depositional substrate, sometimes combined with some type of cover (Prenda et al, 1997). In accordance, Welton et al. (1983) found that, in the Mill Stream (England), stone loach had a clear preference for macrophyte areas with a substratum of silt.

The results for substrate indicated preference for vegetation (usually accompanied with fine substrate) as well as for medium- and large-sized gravel in accordance with the lithophilous character of L. echigonia (Aoyama \& Doi, 2006). Our observations partly coincide with a close relative species of the family Cobitidae in Japan, Cobitis kaibarai (Nakajima, 2012), for which the population seemed to be correlated with emergent hydrophytes with silt substrate in non-spawning season (Kim et al., 2012). Concerning the Eurasian relative stone loach, there is abundant 
information about the preference of juveniles and adults for coarse substratum (Copp \& Vilizzi, 2004). Thus, it is generally considered that stone loach prefers fine-to-mediumsize substrate in rivers (Copp et al., 1994; Zweimüller, 1995), which may be interpreted as a resemblance of the habitat use of L. echigonia. As partly mentioned earlier, the function of medium- and large-sized gravel to alleviate high velocity should also be considered here as observed in the Yagawa River.

The physical habitat simulation in a highly representative river reach (more than a $60 \%$ of the total length) showed an irregular spatial distribution of the suitable habitats, related with microhabitat and mesohabitat types, as well as the high influence of channelised sections (see Figure 4). Nonetheless, the coefficient of correlation between percentage of vegetation and concrete, for all the cross sections, was -0.706 . In urban streams, it is common to observe hydrological and morphological modifications, with consequent morphological adjustments degrading the instream habitats and simplifying the streambed structure leading to pools aggradation and riffles erosion (Gregory et al., 1994). The larger reductions on the AWS were observed in transects located in the upstream segment, with concrete in proportions generally between 20 and $30 \%$ (Figure 4). In these sections, the low flow favours low flow velocities in pools and the opposite in channelised sections where the effect is aggravated because the shelter against swift current provided by natural vegetation is generally scarce. In such conditions, when the flow rises fish tend to avoid environments with large fluctuations in velocity because turbulent flows can cause fish dragging (Hockley et al, 2014). On the contrary, some transects in the downstream segment (generally from section 3 to 22), with a high proportion of vegetation (Figure 4), showed an increase of the AWS for higher flows, regardless the mesohabitat type. These results indicated that bank 
channelisation could nowadays be the main threat for the species conservation, which could be extrapolated to other taxa adapted to such kind of streams.

\section{Conclusions and recommendations}

The habitat time series during more than three years of study, allowed us to confirm that the critical periods, in terms of habitat, for L. echigonia are related with high flows. The optimum habitat conditions occur during a great part of the year, including the breeding season (approximately March-June). However, the critical periods usually start in August, when the juveniles are approximately four months old, thus potentially jeopardizing the sustainability of the fish population. The spatial patterns and the temporal trends described above indicate that during high flows some mesohabitats could offer good protection (small pools in the upper part), but the coincidence of those slow-water mesohabitats with sections where concrete is more abundant is hindering their utility as natural shelter during high flows. Therefore, we hypothesize that high flows and habitat degradation may produce a critical bottleneck in the fish population; this is an aspect that deserves further research in the Yagawa River and other small urban rivers in Japan.

On the other hand, the time series show a relatively consistent pattern of seasonal flows, with small inter-annual variability, which is characteristic of spring-fed river systems, where the aquifer recharge and groundwater quality should be protected. Indeed, urbanisation has hampered rainfall infiltration, which has resulted in decreases or in the worst case depletion of spring water in many parts of Tokyo. To cope with it, Kunitachi City Government has launched the basic plan for water cycle (Kunitachi City Government, 2016) to achieve sustainable water management considering the balance between nature and human water needs. 
Although it is quite difficult in the urbanized areas of Tokyo, where possible, it would be advisable to naturalize the form of the banks to some extent and to facilitate the renaturalisation, in order to facilitate the natural colonisation by aquatic vegetation. Some studies have developed and evaluated pool-riffle structures specifically design for constrained, low gradient channels of urban streams, producing improvements in the mesohabitat structure, fish abundance, biomass and diversity during the two years after construction, especially concerning the fish of slow-water species (Schwartz and Herricks, 2007). In addition, the enhancement of river connectivity is an interesting measure, given the high sensitivity of L. echigonia and other benthic fish to any type of barriers; the conservation of this fish species requires not only the protection of habitats at the local level, but also planning and management at the regional level, considering the river network as the proper study area to maintain the genetic diversity of this species (Mitsuo et al. 2009).

In the general context of urban streams, it becomes relevant the citizens' environmental education and specific programs for citizen science, which can make a difference to involve the neighbours in river conservation and help them understand the importance of conserving and rehabilitating the ecosystems biodiversity (Smith et al. 2016). Taking and processing data, engages people with environmental issues, and surely with their immediate environment (Pocock et al. 2014). For instance, a programme involving school activities on the fish species and the river ecosystem, as well as the citizens' participation in the rehabilitation and monitoring of the Yagawa River, including the river habitats and fish populations, should help river management and conservation. A carefully designed program of citizen science potentially allows to collect data at much larger spatial and temporal extent and much finer resolutions than would otherwise be possible, representing a cost-effective way of collecting such data 
while also providing an excellent opportunity for people to become engaged (Pocock et al. 2014).

In conclusion, this work presents reliable ecological information and the tools needed to help managers conserve the endemic fish species and prioritize actions to rehabilitate urban rivers, not only for L. echigonia but also for other benthic fish species. Finally, this work should also serve as a reference for further ecological studies on habitat use by fish of the family Nemacheilidae and other close relatives in Japan and East Asia.

\section{Geolocation information}

Coordinates of the study site; 139.429210 East; 35.679981 North.

\section{Acknowledgements}

This study was made in part with the support of the JSPS Grants-in-Aid for Scientific Research (Grant number: 17H03886 and 17H04631) and the PROMOE grant for Marina de Miguel Gallo, funded by the Universitat Politècnica de València, between April and August 2018. We thank Dr. Masaomi Kimura, Masato Kondo, Taichi Kasahara, and Akineri Tanaka for their supports in the field survey.

\section{References}

Aoyama S, Doi T, Baba K. 2005. Spawning habits of the fluvial eight-barbel loach Lefua sp. observed in captivity. Ichthyol Res. 52(3):237-242.

Aoyama S, Doi T. 2006. Spawning site of the fluvial eight-barbel loach, Lefua sp., in the natural environment. Ichthyol Res. 53(2):107-112.

Arthington AH, Rall JL, Kennard MJ, Pusey BJ. 2003. Environmental flow requirements of fish in Lesotho Rivers using the DRIFT methodology. River Res Appl. 19:641-666. 
Bovee KD, Lamb BL, Bartholow JM, Stalnaker CB, Taylor J, Henriksen J. 1998. Stream habitat analysis using the instream flow incremental methodology. U.S. Geological Survey, Biological Resources Division Information and Technology Report USGS/BRD-1998-0004. Fort Collins: U.S. Geological Survey.

Bovee KD. 1986. Development and evaluation of habitat suitability criteria for use in the instream flow incremental methodology. U.S. Fish and Wildlife Service Biological Report 86(7).

Coelho D, Hughes SJ, Varandas S, Cortes RMV. 2014. Conservation benefits of riparian buffers in urban areas: the case of the Rio Corgo (north Portugal). Fundam. Appl. Limnol. 185 (1): 55-70.

Copp GH, Warrington S, de Bruine Q. 1994. Comparison of diet in stone loach Barbatula barbatula (L.) and bullhead Cottus gobio (L.) in a small stream. Folia Zool. 43:171-176.

Fukuda S, De Baets B, Waegeman W, Verwaeren J, Mouton AM. 2013. Habitat prediction and knowledge extraction for spawning European grayling (Thymallus thymallus L.) using a broad range of species distribution models. Environ Model Softw. 47:1-6.

Fukuda S, Tanakura T, Hiramatsu K, Harada M. 2015. Ecological Informatics Assessment of spatial habitat heterogeneity by coupling data-driven habitat suitability models with a 2D hydrodynamic model in small-scale streams. Ecological Informatics. 29:147-155.

Fukuda S. 2011. Assessing the applicability of fuzzy neural networks for habitat preference evaluation of Japanese medaka (Oryzias latipes). Ecological Informatics. 6(5):286-295. 
Gregory KJ, Gurnell AM, Hill CT, Tooth S. 1994. Stability of the pool-riffle sequence in changing river channels. Regulated Rivers: Research and Management 9:35-43.

Hayes JW, Jowett IG. 1994. Microhabitat models of large drift-feeding brown trout in three New Zealand rivers. North American Journal of Fisheries Management. $14: 710-725$.

Hockley, F.A., Wilson, C.A.M.E., Brew, A., Cable, J., 2014. Fish responses to flow velocity and turbulence in relation to size, sex and parasite load. J. R. Soc. Interface $11,20130814$.

Hosoya K. 1993. Cobitidae. In: Nakabo T, editor. Fishes of Japan with pictorial keys to the species. Tokyo: Tokai University Press. p. 231-235. (in Japanese)

Jowett IG, Payne T, Milhous R. 2014. SEFA, System for Environmental Flow Analysis. Software Manual Version 1.21.

Kim E, Nakajima J, Onikura N. 2012. Habitat preferences of Cobitis kaibarai (Teleostei: Cobitidae) between spawning and non-spawning seasons in paddy fields, Kyushu Island, Japan. In: Poncin P, Parmentier E, editors. Abstract book-XIV European Congress of Ichthyology. Liège: Université de Liège. p. 115.

King JM, Tharme RE, de Villiers MS, editors. 2008. Environmental Flow Assessments for Rivers: Manual for the Building Block Methodology. WRC Report TT 354/08. Pretoria: Water Research Commission.

Kottelat M. 2012. Conspectus cobitidum: an inventory of the loaches of the world (Teleostei: Cypriniformes: Cobitoidei). Raffles Bulletin of Zoology.

Kunitachi City Government. 2016. Basic Plan for Water Cycle. Kunitachi City: Kunitachi City Government. (in Japanese) 
Lambert TR. 1994. Evaluation of factors causing variability in habitat suitability criteria for Sierra Nevada trout. Environment, Health \& Safety. Report 009.4-94.5. San Francisco: Pacific Gas and Electric Company.

Lee JH, Kil JT, Jeong S. 2010. Evaluation of physical fish habitat quality enhancement designs in urban streams using a 2D hydrodynamic model. Ecol. Eng. 36 (10):12511259.

Martínez-Capel F, García De Jalón D, Werenitzky D, Baeza D, Rodilla-Alamá M. 2009. Microhabitat use by three endemic Iberian cyprinids in Mediterranean rivers (Tagus River Basin, Spain). Fish. Manag. Ecol. 16:52-60.

Martínez-Capel F, García-López L, Beyer M. 2017. Integrating hydrological modelling and ecosystem functioning for environmental flows in climate change scenarios in the Zambezi River (Zambezi region, Namibia). River Res Appl. 33(2):258-275.

Martínez-Capel F. 2000. Preferencias de microhábitat de Barbus bocagei, Chondrostoma polylepis y Leuciscus pyrenaicus en la cuenca del río Tajo. $\mathrm{PhD}$ Dissertation. Madrid: Universidad Politécnica de Madrid. (In Spanish)

Matsuzawa Y, Aoki K, Fukuda, S. 2017a. Critical swimming speed of Lefua echigonia in a laboratory open channel. Proceedings of the Annual Meeting of the Japanese Society of Irrigation Drainage and Reclamation Engineering (JSIDRE). ID: 4-30. Tokyo: Japanese Society of Irrigation Drainage and Reclamation Engineering.

Matsuzawa Y, Ohira M, Fukuda S. 2017b. Microhabitat Modelling for an Endangered Freshwater Fish, Lefua Echigonia, in a Spring-Fed Urban Stream. In: E-Proceedings of the 37th IAHR World Congress. Kuala Lumpur: International Association for Hydro-environment Research and Engineering (IAHR). 
McDonald RI, Güneralp B, Huang C-W, Seto KC, You M. 2018. Conservation priorities to protect vertebrate endemics from global urban expansion. Biol. Conserv. 224:290-299.

Mitsuo Y, Nishida K, Senga Y. 2007. A research on habitat condition of Hotoke loach in "Yatu" waters: case of study of upper stream of the Okuri River. Transaction of JSIDRE 75:445-451 (In Japanese with English abstract)

Muñoz-Mas R, Costa RMS, Alcaraz-Hernández JD, Martínez-Capel F. 2017. Microhabitat competition between Iberian fish species and the endangered Júcar nase (Parachondrostoma arrigonis; Steindachner, 1866). J Ecohydraulics. 2(1):3-15.

Muñoz-Mas R, Lopez-Nicolas A, Martinez-Capel F, Pulido-Velazquez M. 2016. Shifts in the suitable habitat available for brown trout (Salmo trutta L.) under short-term climate change scenarios. Sci Total Environ. 544:686-700.

Muñoz-Mas R, Martínez-Capel F, Schneider M, Mouton AM. 2012. Assessment of brown trout habitat suitability in the Jucar River Basin (SPAIN): Comparison of data-driven approaches with fuzzy-logic models and univariate suitability curves. Sci Total Environ. 440:123-131.

Muñoz-Mas R, Martínez-Capel F, Schneider M, Mouton AM. 2012. Assessment of brown trout habitat suitability in the Jucar River Basin (Spain): Comparison of datadriven approaches with fuzzy-logic models and univariate suitability curves. Sci. Total Environ. 440:123-131.

O'Keeffe J, Quesne TL. 2009. Keeping rivers alive: a primer on environmental flows. Godalming: World Wildlife Fund-UK.

Orth DJ. 1987. Ecological considerations in the development and application of instream flow habitat models. Regul Rivers Res Manag. 1(2):171-181. 
Payne TR, Jowett IG. 2012. SEFA - Computer software system for environmental flow analysis based on the instream flow incremental methodology. In: Mader H, Kraml J, editors. Proceedings of the 9th International Symposium on Ecohydraulics. Vienna: University of Natural Resources and Life Sciences.

Pocock MJO, Chapman DS, Sheppard LJ, Roy HE. 2014. Choosing and Using Citizen Science: a guide to when and how to use citizen science to monitor biodiversity and the environment. Wallingford: Centre for Ecology \& Hydrology.

Poff NL, Allan JD, Bain MB, Karr JR, Prestegaard KL, Richter BD, Sparks RE, Stromberg JC. 1997. The natural flow regime: a paradigm for river conservation and restoration. Bioscience 47 (11):769-784.

Poff NL. 2017. Beyond the natural flow regime? Broadening the hydro-ecological foundation to meet environmental flows challenges in a non-stationary world. Freshw. Biol. n/a-n/a.

Prenda J, Armitage PD, Grayston A. 1997. Habitat use by the fish assemblages of two chalk streams. J Fish Biol. 51(1):64-79.

Recuero E, Cruzado-Cortes J, Parra-Olea G, Zamudio KR. 2010. Urban Aquatic Habitats and Conservation of Highly Endangered Species: The Case of Ambystoma mexicanum (Caudata, Ambystomatidae). Ann. Zool. Fennici 47 (4):223-239.

Reiser DW, Hilgert PJ. 2018. A practitioner's perspective on the continuing technical merits of PHABSIM. Fisheries 43 (6):278-283.

Rosenfeld JS. 2017. Developing flow-ecology relationships: Implications of nonlinear biological responses for water management. Freshw. Biol. 62 (8):1305-1324.

Sardak S, Korneyev M, Dzhyndzhoian V, Fedotova T, Tryfonova O. 2018. Current trends in global demographic processes. Probl. Perspect. Manag. 16 (1):48-57. 
Smith RF, Hawley RJ, Neale MW, Vietz GJ, Diaz-Pascacio E, Herrmann J, Lovell AC, Prescott C, Rios-Touma B, Smith B, Utz RM. 2016. Urban stream renovation: incorporating societal objectives to achieve ecological improvements. Freshw. Sci. $35(1): 364-379$.

Schwartz JS, Herricks EE. 2007. Evaluation of pool-riffle naturalization structures on habitat complexity and the fish community in an urban Illinois stream. River Res Appl. 23(4):451-466.

Souchon Y, Sabaton C, Deibel R, Reiser D, Kershner J, Gard M, Katopodis C, Leonard P, Poff NL, Miller WJ, Lamb BL. 2008. Detecting biological responses to flow management: missed opportunities; future directions. River Res Appl. 24:506-518.

Taniguchi M, Shimada J, Tanaka T, Kayane I, Sakura Y, Shimano Y, Dapaah-Siakwan S, Kawashima S. 1999. Disturbances of temperature-depth profiles due to surface climate change and subsurface water flow: 1 . An effect of linear increase in surface temperature caused by global warming and urbanization in the Tokyo Metropolitan Area, Japan. Water Resour Res. 35(5):1507-1517.

Thomas JA, Bovee KD. 1993. Application and testing of a procedure to evaluate transferability of habitat suitability criteria. Regul Rivers Res Manag. 8:285-294.

Toshishige I, Maruyama T. 2005. The Japanese eight-barbel loach Lefua echigonia, a new record of host fish for glochidia of the freshwater unionid mussel Pronudularia japanensis. Venus. 64(3-4):199-201. (In Japanese with English abstract)

Vollmer D, Prescott MF, Padawangi R, Girot C, Grêt-Regamey A. 2015. Understanding the value of urban riparian corridors: Considerations in planning for cultural services along an Indonesian river. Landsc. Urban Plan. 138:144-154.

Waters BF. 1976. A methodology for evaluating the effects of different stream flows on salmonid habitat. In Orsbom JF, Allman CH, editors. Instream flow needs. Special 
Publication of the American Fisheries Society. p. 254-266. Bethesda: American Fisheries Society.

Welton JS, Mills CA, Rendle EL. 1983: Food and habitat partitioning in two small benthic fishes, Noemacheilus barbatulus (L.) and Cottus gobio (L.). Arch. Hydrobiol. 97. 434-454.

Zweimüller, I., 1995: Microhabitat use by two small benthic stream fish in a 2nd order stream. Hydrobiologia 303, 125-137. 


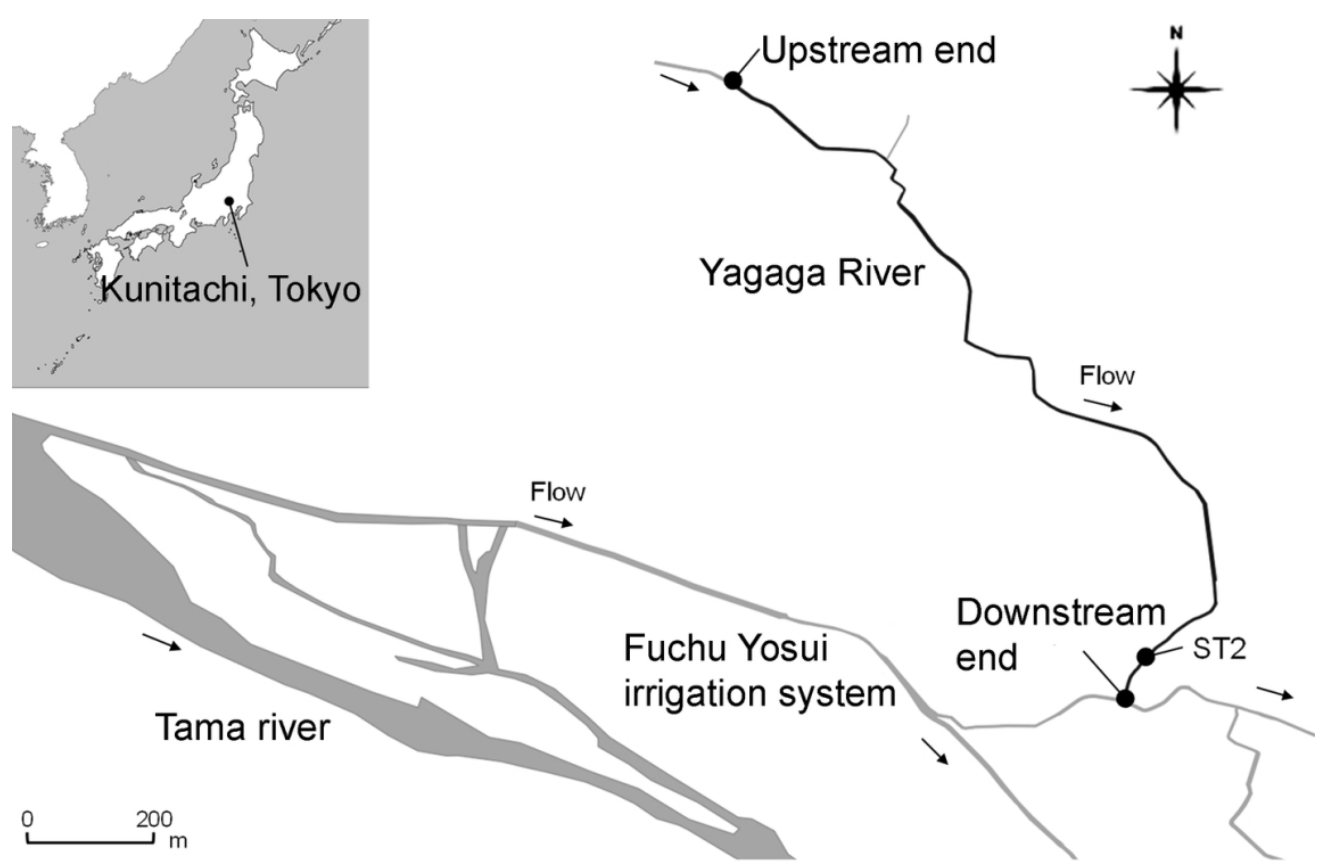

Figure 1. Location of the study area in Kunitachi (Tokyo, Japan), and map showing the upstream and downstream end of the study reach in the Yagawa River. Station 2 near the downstream end (ST2) was selected to display the river flow patterns (Figure 2).

$119 \times 77 \mathrm{~mm}(300 \times 300 \mathrm{DPI})$ 


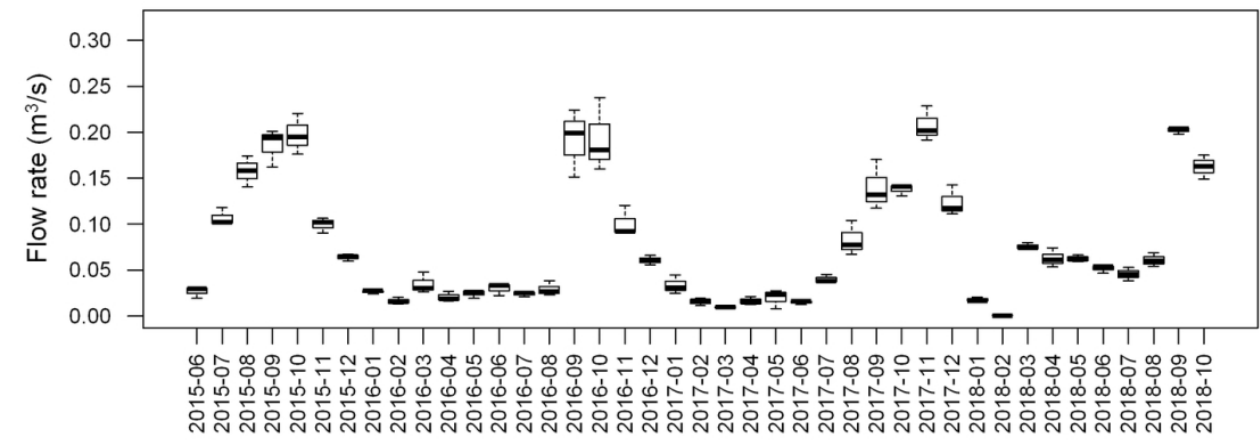

Figure 2. Flow regime $\left(\mathrm{m}^{3} / \mathrm{s}\right)$ monitored monthly at station 2 in the Yagawa River (see Figure 1 ) from June 2015 to October 2018.

$124 \times 47 \mathrm{~mm}(300 \times 300 \mathrm{DPI})$ 
Figure 3. Box-plots showing the habitat variability in the Yagawa River during the study period (June 2015 May 2017) in terms of velocity $(\mathrm{m} / \mathrm{s})$, depth $(\mathrm{m})$ and substrate index (1-6). Substrate codes were; 1 , vegetation; 2 , sand $(<2 \mathrm{~mm}) ; 3$, small-sized gravel $(2-16 \mathrm{~mm}) ; 4$, medium-sized gravel $(16-64 \mathrm{~mm}) ; 5$, large-sized gravel (> $64 \mathrm{~mm}) ; 6$, concrete and continuous rock.

$$
49 \times 104 \mathrm{~mm}(300 \times 300 \mathrm{DPI})
$$


Figure 4. Proportion of substrate types recorded in the field survey in the Yagawa river, at the calibration flow $\left(0.044 \mathrm{~m}^{3} / \mathrm{s}\right)$ per transect (from the downstream to upstream end) over the simulation reach.

\section{$93 \times 51 \mathrm{~mm}(600 \times 600 \mathrm{DPI})$}



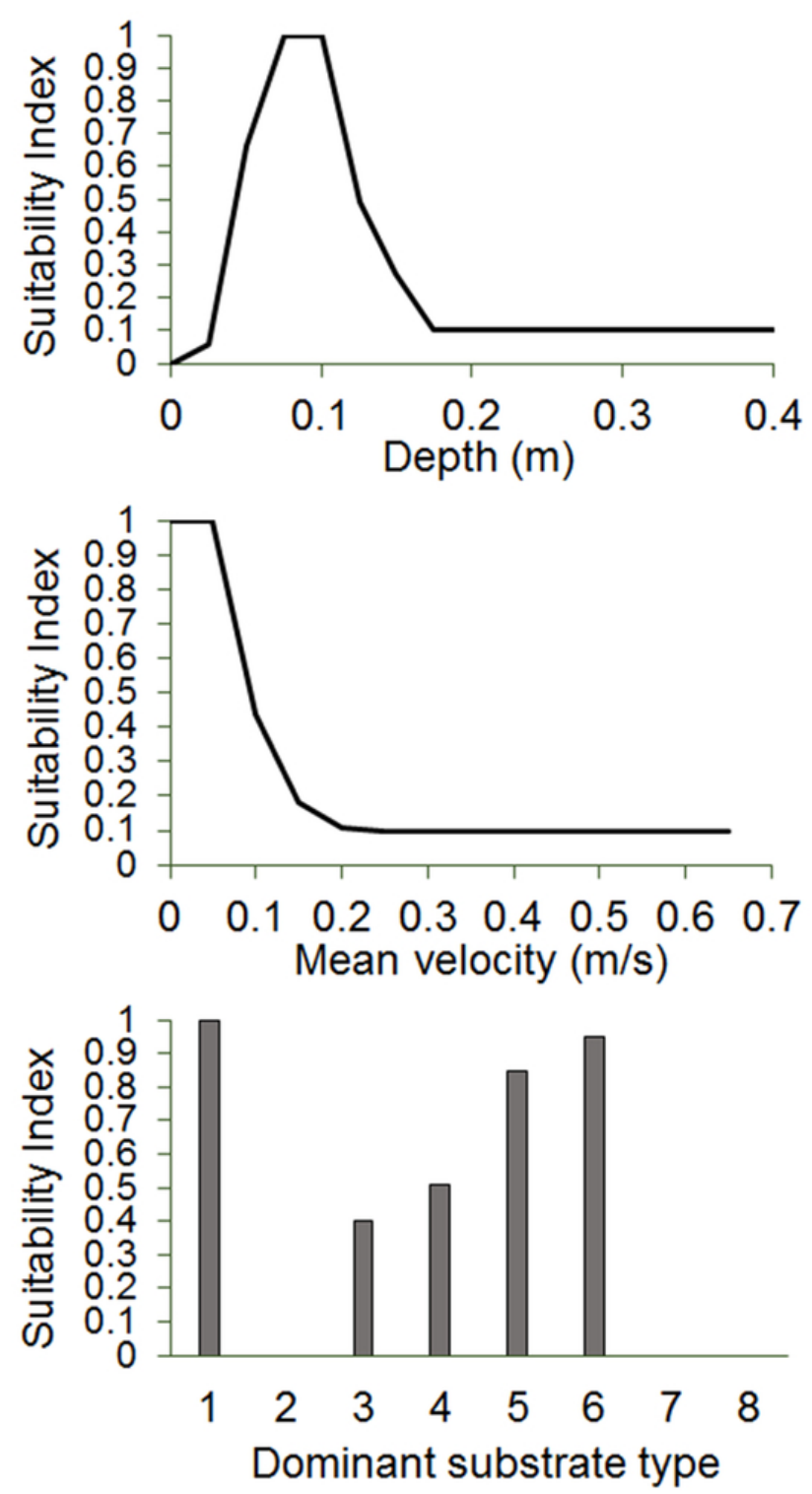

Figure 5. Microhabitat suitability curves for adult Lefua echigonia; (a) depth $(\mathrm{m})$, (b) velocity $(\mathrm{m} / \mathrm{s})$ and (c) dominant substrate type; 1-vegetation; 2-silt; 3-Sand ( $<2 \mathrm{~mm}) ; 4$-small gravel (2-16 mm); 5-mediumsized

gravel (17-64 mm); 6-large-sized gravel (65-256 mm); 7-Boulders (>256 mm); 8-concrete and continuous rock.

$49 \times 87 \mathrm{~mm}(300 \times 300 \mathrm{DPI})$ 
Figure 6. Habitat availability in terms of Area Weighted Suitability (AWS) versus river flow $\left(\mathrm{m}^{3} / \mathrm{s}\right)$; AWS is equal to Weighted Usable Area (WUA) per metre of river length.

$$
104 \times 54 \mathrm{~mm}(300 \times 300 \text { DPI) }
$$




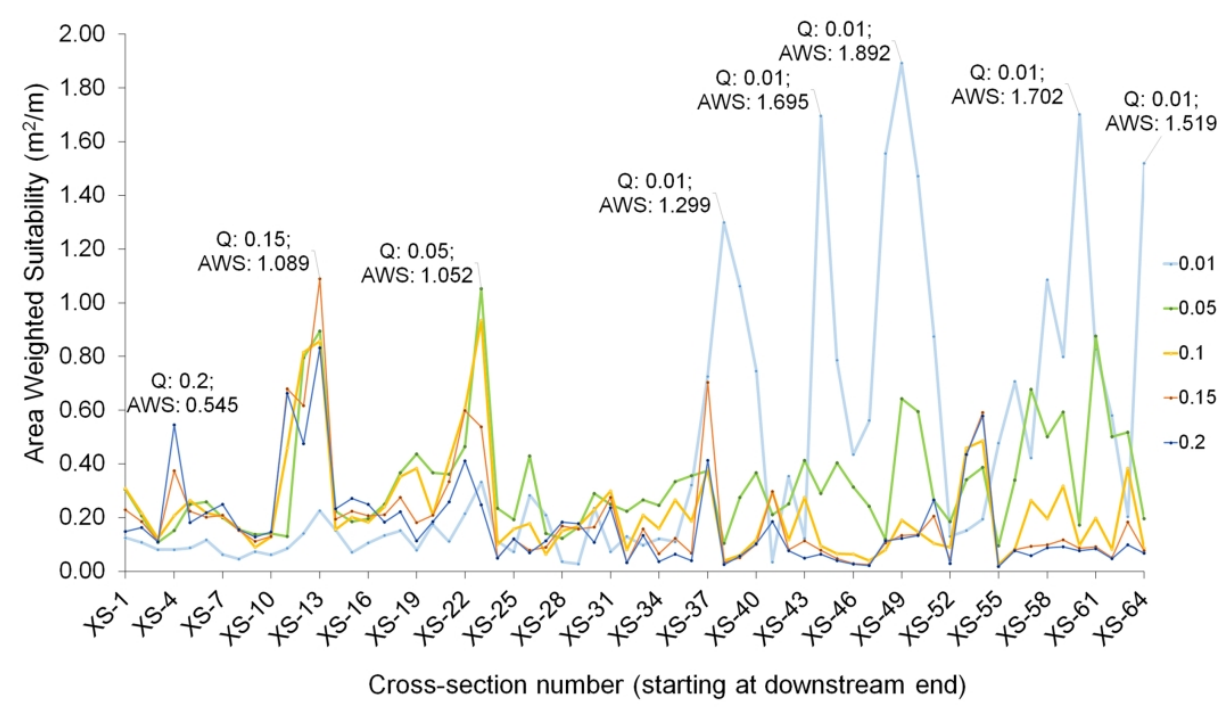

Figure 7. Area Weighted Suitability (AWS) evaluated per transect (from the downstream to upstream end) over the simulation reach, for five values of river flow rate. Transect 4 (XS-4) corresponds to station 2 (see Figure 1).

$114 \times 69 \mathrm{~mm}(600 \times 600 \mathrm{DPI})$ 
Figure 8. River flow recorded in the Yagawa River and Area Weighted Suitability (AWS) evaluated for the period between June 2015 and October 2018.

$126 \times 59 \mathrm{~mm}(300 \times 300 \mathrm{DPI})$ 